\title{
REALISASI TINDAK TUTUR REMAJA ALAYERS PADA AKUN FACEBOOK
}

\author{
(Realization Speak Acts of Youth Alayers on Facebook Account) \\ Irawati Bangun ${ }^{a}$, Ridwan Hanafiah ${ }^{b}$, dan Thyrhaya Zein \\ ${ }^{a}$ (Linguistik, Universitas Sumatera Utara, Indonesia) \\ ${ }^{b}$ (Linguistik, Universitas Sumatera Utara, Indonesia) \\ c(Linguistik, Universitas Sumatera Utara, Indonesia) \\ Ponsel 082277556642
}

Pos-el: bangun_irawati@yahoo.com

tanggal naskah masuk 14 Desember 2018

tanggal akhir penyuntingan 16 Juni 2019

\begin{abstract}
Alay language is one of the new languages that has a negative impact on the existence of Indonesian. because it violates the good and right Indonesian norms and ethics. The purpose of this study is to find out how the realization of Alayers teenage speech acts on Facebook accounts with a sociolinguistic approach. This research is a type of qualitative research that applies content analysis research. The data in this study are words, phrases and sentences in Alay language. Data was sourced from uploading statuses and comments from Alayers in the group A collection of middle / high school kids looking for girlfriends and friends. To collect data in this study, researchers used data collection techniques, namely, observation and substitution techniques. Furthermore, the data was analyzed using the interactive model analysis techniques of Miles, Huberman and Saldana. Based on the results of the study it was found that out of 27 data obtained by researchers, it was found that there were 20 speech acts used by teenagers in uploading their status on Facebook, 5 speech acts in the form of complaints, and 2 more as speech acts in the form of praise. Alayers' teenage talk on Facebook accounts is realized through vulgar sentences and added images and videos containing pornography. The factors that influence adolescent Alayers speech acts on Facebook accounts are: a) Technological sophistication factor; b) Environment and c) Want to get recognition.
\end{abstract}

Keywords: Alay Language, Speech Acts, Sociolinguistics

\section{Abstrak}

Bahasa Alay merupakan salah satu bahasa baru yang berdampak buruk bagi eksistensi bahasa Indonesia, karena dianggap melanggar norma dan etika bahasa Indonesia yang baik dan benar. Adapun tujuan penelitian ini yaitu untuk mengetahui bagaimana realisasi tindak tutur remaja Alayers pada akun Facebook dengan pendekatan sosiolinguistik. Penelitian ini merupakan jenis penelitian kualitatif yang menerapkan penelitian analisis isi (content analysis). Adapun data dalam penelitian ini adalah kata, frasa dan kalimat dalam bahasa Alay. Data bersumber dari unggahan status dan komentar para Alayers di grup 'Kumpulan Anak SMP/SMA Cari Pacar dan Sahabat'. Untuk mengumpulkan data pada penelitian ini, peneliti menggunakan teknik pengumpulan data yaitu, teknik observasi dan subtitusi. Selanjutnya data di analisis dengan menggunakan teknik analisis model interaktif Miles, Huberman dan Saldana. Berdasarkan hasil penelitian diketahui bahwa dari 27 data yang diperoleh peneliti, diketahui bahwa ada 20 tindak tutur permohonan yang digunakan oleh remaja Alayers dalam unggahan statusnya di Facebook, 5 tindak tutur dalam bentuk keluhan, dan 2 lagi merupakan tindak tutur berbentuk Pujian. 
Tindak tutur remaja Alayers pada akun Facebook direalisasikan melalui kalimat-kalimat yang vulgar dan ditambah dengan gambar-gambar serta video yang mengandung pornografi. Adapun faktor yang memengaruhi tindak tutur remaja Alayers pada akun Facebook yaitu: a) Faktor kecanggihan teknologi; b) Lingkungan dan c) Ingin mendapatkan pengakuan.

Kata-kata kunci: Bahasa Alay, Realisasi Tindak Tutur, Sosiolinguistik

\section{PENDAHULUAN}

Di era globalisasi ini bahasa Indonesia yang baik dan benar semakin jarang dipakai terutama dikalangan remaja, karena kemunculan modifikasi gaya bahasa menjadi bahasa gaul. Hal ini dipengaruhi oleh semakin berkembangnya teknologi, terutama berkembangnya situs jejaring sosial, misalnya facebook. Pada tahun 2008 muncul suatu bahasa baru dikalangan remaja yang disebut dengan bahasa "Alay". Penggunaan bahasa Indonesia yang baik dan benar mulai tergusur oleh munculnya bahasa alay, hal ini tampak jelas pada bahasa lisan dan tulis yang sering digunakan oleh masyarakat kita, khususnya dikalangan remaja (Saragih, 2011).

Bahasa Alay dapat dikatakan sebagai turunan dari bahasa slang yang di ubah bentuknya sehingga menciptakan satu bahasa yang baru yaitu bahasa Alay (Saragih, 2011:13). Bahasa Alay dapat diartikan sebagai variasi bahasa yang bersifat sementara yang biasanya berupa singkatan, penggabungan huruf dengan angka, memperpanjang atau memperpendek kata, mencampurkan huruf besar dengan huruf kecil yang membentuk sebuah kata, frasa maupun kalimat.

Pada dasarnya bahasa Alay digunakan oleh anak-anak remaja SMP maupun SMA, yang secara tidak langsung bahasa Alay tersebut menjadi suatu kebudayaan yang baru di kalangan remaja karena digunakan sebagai bahasa seharihari khususnya pada saat berkumpul dengan teman-temannya di sekolah, di cafe bahkan digunakan dalam rumah. Remaja Alayers mencirikan kelompoknya melalui bahasa yang mereka gunakan atau dapat dikatakan sebagai identitas yang membedakan mereka dengan kelompok masyarakat lainnya (Saragih, 2011:18).

Remaja pada umumnya telah melupakan bahkan tidak mengetahui kaidah Ejaan Yang Disempurnakan dalam membuat sebuah karangan, kalimat, atau bahkan menuliskan sebuah kata. Mereka tidak mengerti bagaimana menulis lambang bilangan, penggunaan kata yang tidak baku, ataupun menggunakan akronim yang benar. Ironisnya, seharusnya mereka mampu menggunakan kaidah yang benar dalam menulis karena bahasa Indonesia adalah bahasa bangsa.

Fenomena tersebut di atas menjadi perhatian dari berbagai kalangan karena dianggap tidak mempunyai standar yang pasti. Kehadiran bahasa Alay dianggap sangat mengganggu karena tidak memiliki konsistensi bahasa, seperti bahasa pada umumnya. Selain tidak memiliki standar yang pasti, bahasa Alay juga dapat berpengaruh buruk terhadap eksistensi bahasa Indonesia yang merupakan bahasa nasional, bahasa persatuan, dan bahasa pengantar dalam kehidupan sehari-hari karena remaja Alayers menciptakan bahasa Alay dari bahasa Indonesia yang telah diubah penulisannya sesuai dengan yang mereka inginkan.

Ditinjau dari segi manfaat, bahasa Alay hanya memberikan kesan unik dan menghibur bagi pengguna dan penggemar yang menyukainya khususnya remaja Alayers. Sehingga dampak buruknya adalah pengguna bahasa Alay terkesan melanggar norma dan etika bahasa Indonesia yang baik dan benar dan hal itu merupakan kerugian yang paling fatal karena dapat berpengaruh pada kedudukan bahasa Indonesia sebagai bahasa nasional. 
Dalam melakukan suatu tindak tutur, selain menyatakan maksud dan keinginannya, penutur juga secara alami bertujuan untuk menciptakan dan menjaga hubungan sosial. Oleh sebab itu, bahasa Alay termasuk bahasa yang meresahkan sebagian besar masyarakat karena banyak dari kalangan masyarakat yang tidak memahami bahasa Alay dan kurang menjaga hubungan sosial (Siregar, 2011: 63).

Bahasa Alay erat kaitannya dengan tindak tutur. Austin (1992:64) menyebutkan bahwa pada dasarnya pada saat seseorang mengatakan sesuatu, seseorang tersebut juga melakukan sesuatu. Pernyataan tersebut kemudian mendasari lahirnya teori tindak tutur. Tindak tutur merupakan suatu ujaran yang mengandung tindakan sebagai suatu kesatuan fungsional dalam komunikasi yang mempertimbangkan aspek situasi tutur.

Penelitian tentang ragam bahasa tutur remaja pernah diteliti sebelumnya, seperti pada penelitian yang dilakukan oleh Saleh (2014) dalam jurnal penelitian yang berjudul "Gangguan Bahasa Alay di Facebook terhadap Komunikasi" berpendapat bahwa bahasa Alay menjadi pemicu munculnya gangguan terhadap komunikasi khususnya pada media sosial facebook karena kata-kata yang digunakan dalam bahasa Alay tersebut sulit dimengerti oleh khalayak tertentu, bahasa yang digunakan oleh penutur berbeda dengan bahasa yang digunakan oleh penerima tuturan, dan yang terakhir struktur bahasa yang berantakan sehingga menyebabkan miskomunikasi. Adapun tujuan penelitian ini yaitu untuk menganalisis realisasi ujaran remaja Alayers pada akun Facebook.

\section{PEMBAHASAN}

Berikut ini dipaparkan pembahasan tentang realisasi dan faktor penyebab tindak tutur Alayers pada akun Facebook.

\section{Realisasi Tindak Tutur}

Adapun realisasi tindak tutur remaja alayers tersebut yaitu yaitu sebagai berikut:

\section{Data 01}

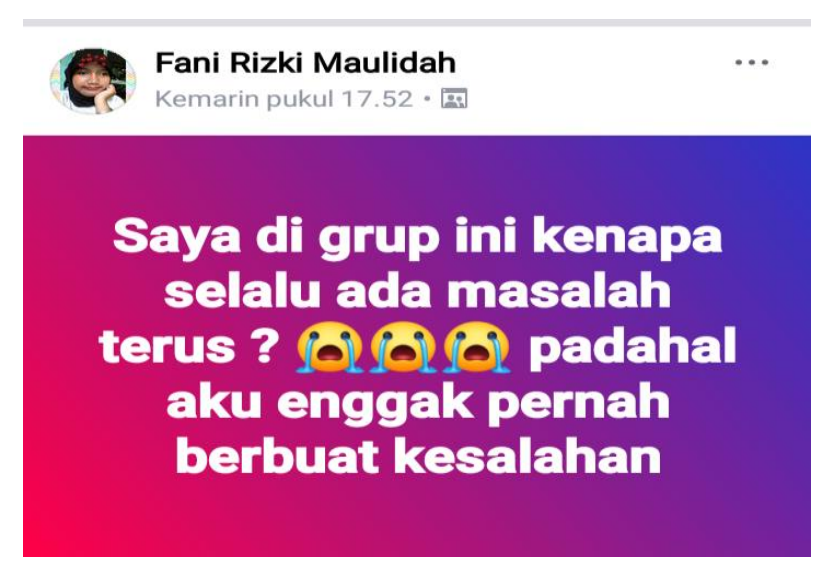

\section{Gambar 1 Realisasi Tindak Tutur Keluhan Remaja Alayers}

Pada data 1 di atas, remaja Alayers pada grup akun facebook remaja alayers yaitu Kumpulan Anak SMP/SMA Cari Pacar dan Sahabat menggunakan tindak tutur keluhan. Tindak tutur keluhan tersebut adalah salah satu cara remaja Alayers yang bernama Fani Rizki Maulidah untuk memancing orang memberikan komentar terhadap unggahannya. Tindak tutur tersebut direalisasikan melalui kalimatkalimat Alay yang di dukung oleh emoticon yang mendeskripsikan suasana hatinya pada saat mengunggah status tersebut.

Selain itu, remaja Alayers yang bernama Fani Rizki Maulidah juga menggunakan kalimat yang sedih, yang bertujuan untuk menarik perhatian anggota group yang sedang online, sehingga anggota group yang sedang online tersebut membaca unggahannya dan terpancing untuk merespon statusnya dengan komentar negatif maupun komentar positif.

\section{Data 02}

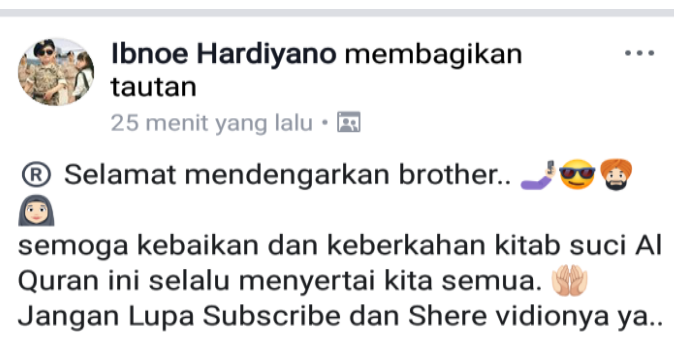
Gambar 2 Realisasi Tindak Tutur
Permohonan Remaja Alayers 
Pada data 2 di atas, remaja Alayers pada grup akun facebook remaja alayers yaitu Kumpulan Anak SMP/SMA Cari Pacar dan Sahabat yang memiliki nama akun facebook Ibnoe Hardiyano menggunakan bentuk tindak tutur permohonan. Tindak tutur keluhan tersebut direalisasikan melalui melalui kata-kata yang Alay dan dikemas seunik mungkin, misalnya dengan menggunakan kata-kata yang bersifat keagamaan, padahal apabila di simak tidak ada kaitannya antara lagu yang diputar dengan kata-kata yang bersifat keagamaan tersebut.

Akun facebook Ibnoe Hardiyano tersebut membuat ungahannya seunik mungkin yang bertujuan untuk menarik perhatian anggota group yang sedang online, sehingga anggota group yang sedang online tersebut membaca unggahannya dan terpancing untuk merespon. Selain itu, adapun tujuan dari realisasi ujaran tersebut yaitu agar para anggota group yang sedang online dan membaca kirimannya menyempatkan diri untuk sekedar mensubscribe dan membagikan videonya.

\section{Data 03}

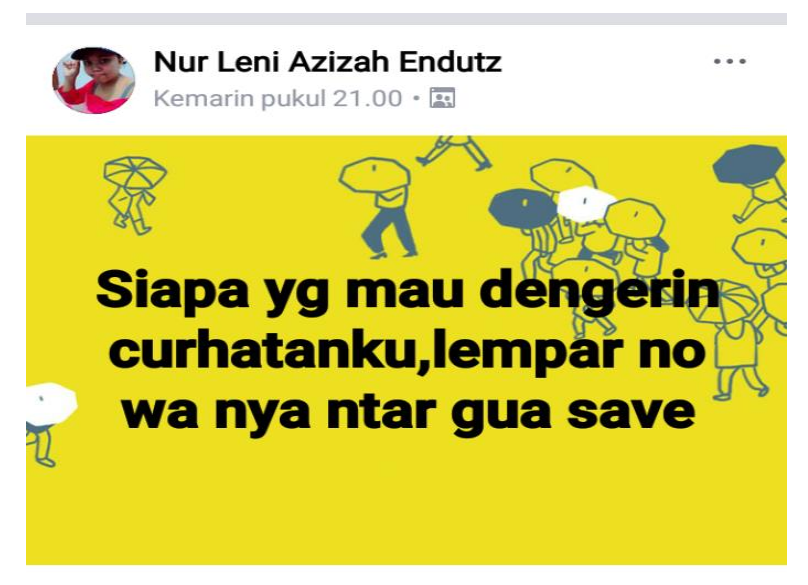

\section{Gambar 3 Realisasi Tindak Tutur Terima Kasih Remaja Alayers}

Pada data 3 di atas, remaja Alayers pada grup akun facebook remaja alayers yaitu Kumpulan Anak SMP/SMA Cari Pacar dan Sahabat yang memiliki akun facebook bernama Nur Leni Azizah Endutz menggunakan tindak bentuk tindak tutur terima kasih. Tindak tutur terima kasih tersebut direalisasikan melalui kalimat yang menunjukkan ungkapan terima kasih apabila ada anggota group yang mau mendengarkan curhatannya melalui sosial media, dan sebagai rasa ungkapan terima kasihnya maka remaja Alayers yang memiliki akun facebook bernama Nur Leni Azizah Endutz tersebut akan menyimpan nomor Whatsap dari orang tersebut.

\section{Data 04}

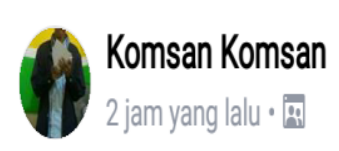

cwe yang mau 300 ,inbox aja .

pacaran aja .no sex

jakarta.

\section{(1)2 1Komentar}

\section{Gambar 4 Realisasi Tindak Tutur permohonan Remaja Alayers}

Pada data 4 di atas, remaja Alayers pada grup akun facebook remaja alayers yaitu Kumpulan Anak SMP/SMA Cari Pacar dan Sahabat yang memiliki akun facebook bernama Komsan Komsan menggunakan bentuk tindak tutur permohonan. Bentuk tindak tutur permohonan tersebut direalisasikan melalui kalimat yang intinya adalah iming-iming hadiah uang sebesar Rp. 300.000 apabila ada anggota group perempuan yang mau mengirimi pesan melalui inbox kepada akun Facebooknya.

Bentuk tindak tutur yang digunakan oleh akun tersebut di perhalus dengan mengatakan bahwa ketika ada ada anggota group perempuan yang mau mengiriminya pesan melalui inbox maka tidak akan ada topik mengenai seks, namun hanya berupa ajakan berpacaran semata. 
Data 05

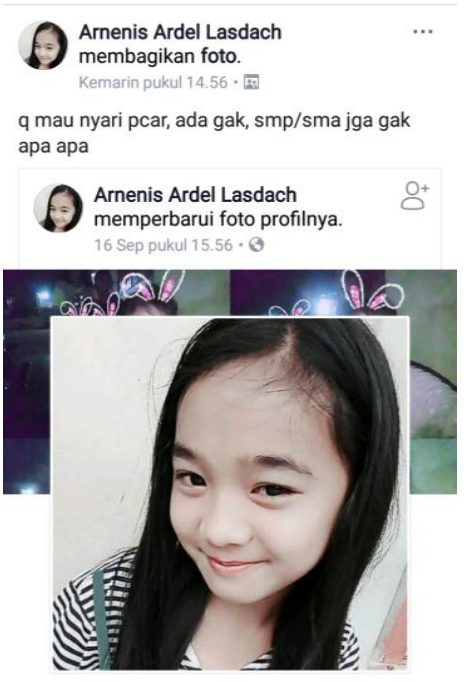

\section{Gambar 5. Realisasi Tindak Tutur permohonan Remaja Alayers}

Pada data 5 di atas, remaja Alayers pada grup akun facebook remaja alayers yaitu Kumpulan Anak SMP/SMA Cari Pacar dan Sahabat yang memiliki akun facebook bernama Armenia Ardel Lasdach menggunakan bentuk tindak tutur permohonan. Bentuk tindak tutur permohonan tersebut direalisasikan ke dalam bentuk kalimat yang dapat mengundang anggota group lainnya khususnya laki-laki untuk bersedia menjadi pacar dari akun akun facebook bernama Armenia Ardel Lasdach. Jika ada dari anggota group tersebut yang bersedia menjadi pacar dari akun facebook remaja Alayers yang bernama Armenia Ardel Lasdach tersebut baik itu anak SMA maupun SMP dia akan jadikan sebagai pacar. .

Selain itu, untuk menarik perhatian para anggota group yang lain, remaja Alayers yang memiliki akun facebook bernama Armenia Ardel Lasdach mengunggah fotonya yang unik, agar semakin membuat anggota group lainnya mengomentari unggahannya tersebut.
Data 06

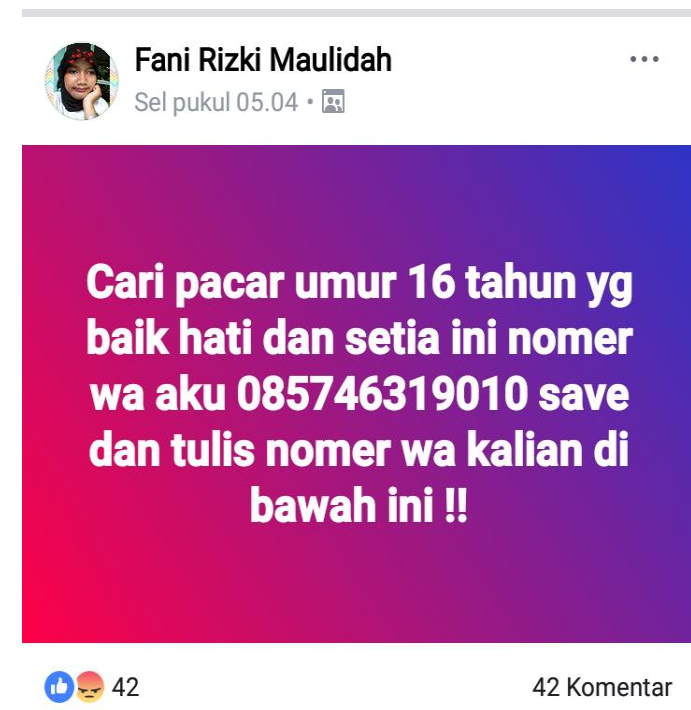

\section{Gambar 6 Realisasi Tindak Tutur permohonan Remaja Alayers}

Pada data 6 di atas remaja Alayers Alayers pada grup akun facebook remaja alayers yaitu Kumpulan Anak SMP/SMA Cari Pacar dan Sahabat yang memiliki akun facebook bernama Fani Rizki Maulidah menggunakan bentuk tindak tutur permohonan, yaitu permohonan kepada orang-orang agar bersedia menjadi pacar dari akun facebook remaja Alayers yang bernama Fani Rizki Maulidah tersebut.

Tindak tutur permohonan tersebut direalisasikan melalui kalimat Alay yang seolah-olah hendak mempromosikan dirinya, seperti menyatakan bahwa dirinya adalah seorang gadis berusia 16 tahun, memiliki karakter yang baik hati dan setia, serta memberikan nomor whatsap pribadinya. 
my ig anatasya_17

yg gila vc atau vcs saya blok langsung...kirim

foto wajahnya dulu baru wa lanjut ....ku cari

cowok kurus putih dan baby face ....anak

sekolah

my wa 082162948018

\section{Gambar 7 Realisasi Tindak Tutur permohonan Remaja Alayers}

Pada data 7 di atas, remaja Alayers Alayers pada grup akun facebook remaja alayers yaitu Kumpulan Anak SMP/SMA Cari Pacar dan Sahabat yang memiliki akun facebook bernama Anastasya Putri Utami menggunakan bentuk tindak tutur permohonan. Tindak tutur permohonan tersebut direalisasikan melalui kalimatkalimatnya yang mengundang kontroversi, yaitu membuat spesifikasi oang-orang yang mau dijadikan teman chat di instagram milik pribadinya, yaitu cowok kurus, putih dan baby face.

Bahasa yang digunakan pada realisasi tindak tutur ini juga dibuat selucu mungkin, dengan tujuan agar dapat membuat oranglain tertarik untuk memberikan komentar terhadap unggahan statusnya Alayers pada grup akun facebook remaja alayers yaitu Kumpulan Anak SMP/SMA Cari Pacar dan Sahabat tersebut.

\section{Data 08}

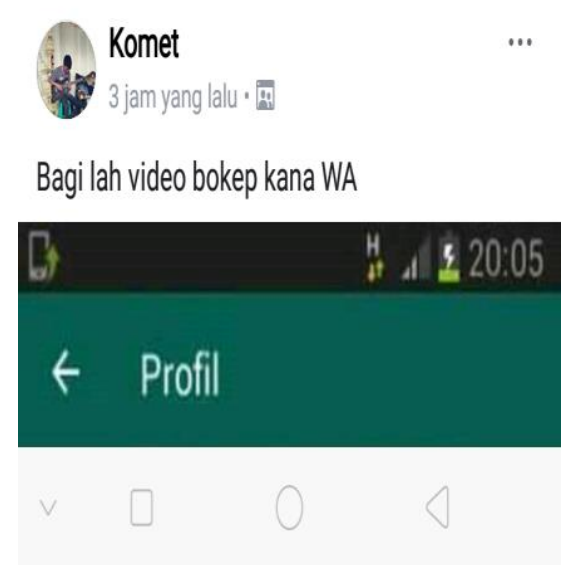

\section{Gambar 8 Realisasi Tindak Tutur permohonan Remaja Alayers}

Pada data 8 di atas, remaja Alayers Alayers pada grup akun facebook remaja alayers yaitu Kumpulan Anak SMP/SMA Cari Pacar dan Sahabat yang memiliki akun facebook bernama komet menggunakan bentuk tindak tutur permohonan yang bertujuan untuk memohon kepada para anggota group agar bersedia memberikan video bokep kepada akun facebook remaja Alayers yang bernama komet tersebut melalui Whatsap.

Tindak tutur permohonan tersebut ditunjukkan direalisasikan melalui kalimat yang seolah-olah memelas dan meminta bantuan dari anggota pada Alayers pada grup akun facebook remaja alayers yaitu Kumpulan Anak SMP/SMA Cari Pacar dan Sahabat lainnya.

\section{Data 09}

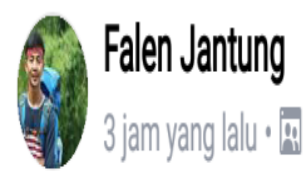

CERTTAZEXYUKYNG MAUAJAH

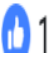

Gambar 9 Realisasi Tindak Tutur
permohonan Remaja Alayers 
Pada data 9 di atas, remaja Alayers pada grup akun facebook remaja alayers yaitu Kumpulan Anak SMP/SMA Cari Pacar dan Sahabat lainnya yang memiliki akun facebook bernama Falen Jantung menggunakan bentuk tindak tutur permohonan, yaitu permohonan kepada orang-orang agar bersedia bercerita tentang hal-hal seksual dengannya.

Tindak tutur permohonan tersebut direalisasikan melalui kalimat bujukan untuk mau melakukan chating seks dengan anggota group yang bersedia. Kemudian remaja Alayers yang memiliki akun facebook bernama Falen Jantung tersebut juga menggunakan foto profil yang semenarik mungkin yang membuat lawan jenisnya bersedia untuk di ajak melakukan chating seks dengan dirinya.

\section{Data 10}

\section{Indra 3 jamyang lalu 10

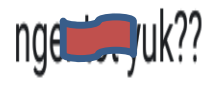 \\ Gambar 10 Realisasi Tindak Tutur permohonan Remaja Alayers}

Pada data 10 di atas, remaja Alayers pada grup akun facebook remaja alayers yaitu Kumpulan Anak SMP/SMA Cari Pacar dan Sahabat yang memiliki akun facebook bernama Indra menggunakan bentuk tindak tutur permohonan, yaitu permohonan kepada orang-orang agar bersedia bercerita melakukan hal seksual dengannya. Tindak tutur permohonan tersebut direalisasikan melalui unggahan yang dapat membuat orang tertarik untuk menanggapinya, yaitu dengan menggunakan kata-kata yang vulgar yaitu “ ngentot" atau berhubungan badan.

Selain itu, untuk membuat orang lain mengomentari statusnya tersebut, maka remaja Alayers yang memiliki akun facebook bernama Indra juga membuat foto profilnya sekeren mungkin, sehingga anggota group yang berbeda jenis kelamin dengannya pada grup akun facebook remaja alayers yaitu Kumpulan Anak SMP/SMA Cari Pacar dan Sahabat agar tertarik untuk mengomentari statusnya.

\section{Faktor Penyebab Tindak Tutur

Remaja Alayers pada Akun
Facebook

Ada beberapa faktor yang menyebabkan remaja Alayers menggunakan sebuah tindak tutur tertentu. Pada penelitian ini, peneliti paparkan beberapa faktor yang tidak bisa lepas dari remaja tersebut, yakni:

\section{1) Pengaruh Perkembangan Teknologi}

Perkembangan teknologi dan informasi saat ini memungkinkan semua kalangan dapat mengakses internet dengan mudah, mulai dari kalangan masyarakat kelas sosial atas hingga masyarakat kelas bawah, termasuk kalangan pelajar atau dalam hal ini remaja SMP dan SMA. Internet sendiri merupakan akronim dari interconnection networking yang diartikan hubungan komputer dengan berbagai tipe yang membentuk sistem jaringan yang mencakup seluruh dunia (jaringan komputer global) dengan melalui jalur telekomunikasi seperti telepon seluler, satelit dan lainnya. Melalui jaringan internet, pemakaian gadget di seluruh dunia dimungkinkan untuk saling berkomunikasi.

Melalui kecanggihan internet orang yang satu dengan orang yang lain dapat mempertukarkan informasi dengan memanfaatkan berbagai fitur yang ada, menikmati hiburan dalam berbagai bentuk, membina hubungan antar pribadi serta dapat digunakan sebagai media sosial untuk memperluas interaksi antarpribadi.

Internet memang memudahkan semua aspek kehidupan dalam mengakses beragam situs sesuai dengan kebutuhan 
pengguna jasa alat elektronik modern tersebut yang berkaitan dengan bisnis, hobi, pendidikan, pertemanan, bahkan transaksi dapat dilakukan melalui internet. Pentingnya keberadaan internet mendorong sebagian orang untuk terhubung dengan jaringan internet.

Namun sering kali internet tersebut juga memberikan dampak yang berbahaya pada remaja, khususnya remaja Alayers yang tidak memiliki filter dalam menerima setiap informasi yang disuguhkan oleh internet dan remaja tersebut yang tanpa sengaja mendapatkan informasi dari website ketika melakukan surfing atau mendapatkan kiriman berisi konten pornografi, juga ketika melakukan chatting (diskusi) di jejaring sosial tanpa disengaja mendapatkan kiriman link (jaringan) konten porno.

Mudah dan murahnya mendapatkan layanan internet serta kurangnya pengawasan dalam mengakses internet, membuat remaja Alayers menggunakan layanan internet untuk mengakses materi pornografi. Materi porno berupa cerita, gambar, video dan chatting yang dapat diperoleh dengan mudah hanya dengan menggunakan kuota atau bahkan memanfaatkan wifi ditempat-tempat tongkrongan. Hal-hal yang berbau sensual juga sangat mudah didapatkan di internet. Semua orang bisa mengkonsumsi dan mengakses pornografi di media internet, termasuk remaja Alayers.

Diketahui bahwa remaja merupakan fase dimana kematangan organ seksualnya sudah mulai bekerja mengakibatkan nafsu seksualnya sudah tumbuh, sehingga remaja cenderung berminat membicarakan, mempelajari atau mengamatisegala hal yang berbau seksual. Hal itu dapat mengacu pada terjadinya perubahan perilaku remaja khususnya remaja Alayers

Diketahui bahwa media massa atau dalam hal ini internet memberikan dampak yang besar terhadap perubahan perilaku dan persepsi para remaja, khususnya remaja
Alayers selaku penggunaanya. Peneliti beranggapan bahwa salah satu faktor terbesar remaja melakukan perilaku seksual seperti berbicara tentang hal-hal yang vulgar adalah karena terlalu sering melihat konten porno di internet terutama video porno. Mengapa demikian, karena dengan melihat hal-hal yang berbau seksual akan berpengaruh secara kognitif serta dapat merefleksikan aktivitas tersebut dalam bentuk imajinasi dan tindakan dari remaja tersebut. Hal tersebut dianggap menyenangkan dan menghibur sehingga cenderung melakukan aktivitas tersebut secara menetap.

Fakta yang lainnya bahwa remaja Alayers dapat dengan leluasa mengakses konten porno di internet dimana saja baik di rumah di lingkungan sekolah, warnet, warung kopi dan lain sebagainya, hal ini membuktikan terpaan pornografi khusunya dalam bentuk video mempunyai pengaruh yang besar terhadap perilaku seksual menyimpang yang selama ini terjadi dikalangan remaja khususnya remaja Alayers.

Selain bertentangan dengan nilainilai moral dalam masyarakat perilaku seksual menyimpang juga dilarang oleh agama. Agama sangat menentang keras seks bebas ataupun mengumbar-ngumbar aurat karena di dalam agama islam laki-laki dan wanita harus menahan padangan dan menjaga organ reproduksinya dari apapun yang di haramkan. Namun apa yang terjadi saat ini, fenomena seks bebas bukan lagi sesuatu yang asing dikalangan masyarakat.

Salah satu pelaku dalam video porno sendiri adalah kalangan remaja Alayers, lihat saja bagaimana penyebaran video mesum yang sebagian besar pelakunya berasal dari kalangan siswa - siswi remaja SMP dan SMA yang ada di seluruh kota di Indonesia.

Masalah tindak tutur remaja yang vulgar menjadi keprihatinan semua kalangan. Hal inilah yang seharusnya menjadi fokus perhatian pihak sekolah dan 
para orang tua, maupun pemerintah dalam memperbaiki moral generasi muda. Beberapa kasus perilaku seksual khususnya dalam bertindak tutur yang dilakukan dikalangan remaja Alayers yang menjadi sorotan media.

Maka dari itu, terpaan pornografi di internet sangat beresiko menimbulkan dorongan seksual remaja. Apalagi bila remaja tersebut sudah mengalami ketergantungan terhadap internet khususnya konten yang berisi pornografi. Hal inilah yang kemudian dapat memicu kemorosotan moral remaja untuk melakukan perilaku seksual menyimpang khususnya dalam bertindak tutur.

\section{2) Pengaruh Lingkungan}

Pada zaman yang serba canggih ini, banyak remaja yang terjerumus terhadap pergaulan bebas yang tidak sehat, apalagi remaja tersebut ingin mendapatkan pengakuan, atau yang sering disebut sebagai anal Alayers. Contohnya saja, demi mendapatkan pengakuan keren dari lawan jenisnya bahkan dari sesama gender, banyak remaja yang rela menjual keperawanannya bahkan sapai hamil diluar nikah, merokok di tempat umum tidak perduli apakah itu remaja Laki-laki atau perempuaan, memakai obat-obatan terlarang, perkelahian, dan sebagainya. Hal itu disebabkan karena faktor lingkungan yang memengaruhi pergauslan mereka. Yaitu lingkungan yang mengharuskan remaja Alayers harus bertingkah seperti remaja Alayers lainnya yangg terlihat lebih funky.

Secara konseptual, lingkungan merupakan faktor yang sangat berpengaruh terhadap perkembangan anak remaja. Faktor-faktor yang mempengaruhi perilaku tingkah laku anak remaja yaitu lingkungan keluarga, lingkungan sekolah, dan lingkungan masyarakat.

Lingkungan keluarga merupakan peranan yang sangat penting terhadap tingkah laku anak remaja khususnya anak Alayers, terutama penciptaan pergaulan yang sehat. Betapa pentingnya peranan anak remaja dalam menentukan masa depan bangsa dan Negara. Sebab, anak remaja juga generasi penerus perjuangan bangsa. Lingkungan keluarga merupakan aspek yang pertama dan utama dalam mempengaruhi perkembangan tingkah laku anak remaja.

Anak remaja lebih banyak menghabiskan waktu di lingkungan keluarga, sehingga keluarga mempunyai peran yang banyak dalam membentuk perlaku dan kepribadian tingkah laku anak remaja serta memberi contoh nyata kepada anak remaja.

Lingkungan sekolah dan lingkungan masyarakat juga berpengaruh dalam perkembangan tingkah laku anak remaja. Lingkungan sekolah mempunyai peranan dalam mengembangkan potensi pengetahuan dan keterampilan yang dimiliki anak remaja, menciptakan budi pekerti yang luhur, membangun solidaritas terhadap sesama yang tinggi, serta mengembangkan keimanan dan ketakwaan anak remaja agar menjadi manusia yang beragama dan beramal kebajikan.

$\begin{array}{crr}\text { Di } & \text { lingkungan } & \text { masyarakat } \\ \text { mempunyai } & \text { peranan } & \text { dalam }\end{array}$ mengembangkan perilaku dan kepribadian anak remaja. Dalam masyarakat anak bergaul dengan teman sebayanya maupun yang lebih mudah atau bahkan yang lebih tua. Dari pergaulan inilah anak remaja akan mengetahui bagaimana orang lain berperilaku dan anak remaja dapat mengetahui peristiwa-peristiwa yang terjadi dalam masyarakat serta anak remaja dapat berpikir dan mencari penyelesaiannya.

\section{3) Ingin Mendapat Pengakuan dari \\ Orang Lain}

Masa remaja merupakan masamasa dimana seseorang sedang mencari identitas, ingin mendapat pengakuan, dan masih sangat labil sehingga remaja sering memiliki hasrat untuk meniru segala sesuatu yang dianggapnya menarik tanpa 
melihat sisi negatif yang akan ditimbulkan. Hal yang dominan terjadi pada tahapan ini adalah pencarian dan pembentukan identitas.

Remaja ingin diakui sebagai individu unik yang memiliki identitas sendiri yang terlepas dari dunia anak-anak maupun dewasa. Penggunaan bahasa baru ini merupakan salah satu bagian dari proses perkembangan mereka sebagai identitas independensi mereka dari dunia orang dewasa dan anak-anak".

Hal itulah yang mendorong remaja untuk menggunakan bahasa alay. Para remaja Alayers menganggap bahwa bahasa alay itu sangat menarik. Pada awalnya mungkin remaja Alayers hanya mendengar bahasa alay dari orang lain dan tidak mengerti apa maksud dari bahasa alay yang orang lain katakan tersebut, namun karena remaja Alayers merasa bahasa alay tersebut sangat menarik, maka remaja Alayers berusaha untuk mencari tahu dan mempelajarinya.

Setelah itu, remaja Alayers akan merealisasikan bahasa alay tersebut dalam kehidupan sehari-hari mereka. Selain itu, remaja tidak ingin selalu terpaku dalam bahasa baku, yang harus digunakan dengan baik dan benar sesuai dengan kaidah yang dianjurkan. Seperti yang diketahui bahwa remaja tidak begitu suka dengan adanya aturan-aturan.

Itulah sebabnya mengapa remaja Alayers lebih banyak memilih menggunakan bahasa alay daripada bahasa Indonesia. Apalagi beberapa dari mereka beranggapan bahwa bahasa alay adalah bahasa gaul, sehingga seseorang yang tidak menggunakannya akan dianggap kuno, ketinggalan jaman, bahkan 'ndeso' yang berarti kampungan.

Dengan adanya pernyataan tersebut, maka remaja Alayers akan semakin tertantang dan berlomba-lomba untuk mencari tahu bahkan menciptakan sendiri bahasa-bahasa yang menurut mereka pantas untuk disebut sebagai bahasa alay dan dapat digunakan oleh remajaremaja lainnya.

Kebanyakan dari mereka yang menggunakan bahasa alay tidak begitu mengerti dan memahami pentingnya berbahasa Indonesia dengan baik dan benar. Jika hal itu dibiarkan, maka akan berdampak buruk bagi pertumbuhan dan perkembangan bahasa Indonesia di negara ini. Antara lain, remaja akan sulit untuk berbahasa Indonesia dengan baik dan benar.

Padahal di sekolah maupun ditempat kerja nanti, setiap orang diharuskan untuk menggunakan Bahasa Indonesia dengan baik dan benar. Tidak mungkin jika ulangan atau tugas dikerjakan menggunakan bahasa alay. Selain itu, penggunaan bahasa alay dapat mengganggu siapapun yang membaca dan mendengar kata-kata yang dimaksud.

Bahkan dapat juga terjadi kesalahpahaman antar orang yang berkomunikasi atau dapat saja terjadi salah persepsi, karena sulit dipahami saat bahasa tersebut digunakan sebagai pengucapan dan sulit dibaca saat digunakan sebagai penulisan. Karena tidak semua orang mengerti akan maksud dari kata-kata alay tersebut. Hal itu sangat memusingkan dan membutuhkan waktu yang lama untuk sekedar memahaminya.

Dengan penggunaan bahasa alay oleh remaja yang semakin berkembang ini, bisa jadi suatu saat nanti anak cucu kita (masyarakat) sudah tidak lagi mengenal bahasa baku dan tidak lagi memakai EYD (Ejaan Yang Disempurnakan) sebagai pedoman dalam berbahasa, kemudian menganggap remeh bahasa Indonesia.

Jika hal ini terus berlangsung, di khawatirkan akan menghilangkan budaya berbahasa Indonesia di kalangan remaja bahkan dikalangan anak-anak. Padahal bahasa Indonesia merupakan bahasa resmi dan juga sebagai identitas bangsa. Oleh karena itu, sebagai generasi penerus bangsa, harusnya mampu menjadi tonggak 
dalam mempertahankan bangsa Indonesia ini.

\section{PENUTUP}

Hasil penelitian ini dapat digunakan sebagai referensi untuk peneliti selanjutnya dalam melakukan penelitian yang berkaitan dengan tindak tutur pada remaja Alayers.

Hasil penelitian ini dapat digunakan untuk memahami perilaku hidup remaja dan dapat meyelesaikan permasalahanpermasalahan hidup mereka berdasarkan lingkup pergaulan mereka.

\section{DAFTAR PUSTAKA}

Alwasilah, Chaedar. (1985). Sosiologi Bahasa. Bandung. Angkasa.

Austin. (1992). How to Do Things with Words. London. Oxford University Press.

Bachman.(1990). Keragaman Bahasa dalam Pembelajaran. Bandung. FPBSUPI.

Chaer, Abdul. (2006). Linguistik Umum. Jakarta: Rineka Cipta.

Chaer, Abdul dan Agustina, Leonie (2010). Sosiolinguistik. Perkenalan Awal. Jakarta: Rineka Cipta.

Cohen, Manion dan Morrison. (2007). Research Methods in Education (6 th ed.) London, New York: Routllege Falme

Crowley. (1999). The Van Hiele Model of the Development of Geometric Thought. Dalam Lindquist, M.M and Shulte, A.P. (Eds.), Learning and Teaching Geometry, K-12. Reston VA: National Council of Teachers of Mathematics.

Damono, Sapardi Djoko. (2002). Pedoman Penelitian Sosiologi Sastra. Jakarta: Pusat Bahasa.

Djokokentjono. (2014). Bahasa dan Masyarakat. Rowley: Newbury House Publishers, inc.

Hanafiah, Ridwan. (2014). Lexical density and grammatical intricacy in linguistic thesis abstract: A qualitative content analysis. Proceedings of English Education International Conference.

Hanafiah, Ridwan. (2011). Pemilihan Bahasa dan Sikap Bahasa dalam Komunikasi Politik Oleh Partai Politik Lokal di Pemerintahan Aceh. Desertasi. Medan: Universitas Sumatera Utara.

Koentjaraningrat. (2015). Pengantar Ilmu Antropologi. Jakarta: Rineka Cipta.

Kridalaksana, Harimurti et al. (2003). Wicara (Pengantar Bahasa dan Kebudayaan Jawa). Jakarta: PT Gramedia Pustaka Utama.

Lakoff. (1977). Politeness Principles.Berkeley: University of California.

Leech, Geoffrey. (1993). Principles of Pragmatics. Singapore: Longman Singapore Publisher.

Malmkjer. (2006). The Linguistik Encyclopedia. London: Routledge.

Meyke, Wardana, dan Trianto. (2014). Penggunaan Kosakata Alay oleh Remaja pada Facebook di Kota Bengkulu. Tesis tidak diterbitkan. Bengkulu: PS PBSI, FKIP Universitas Bengkulu.

Miles,M.B, Huberman, A.M, dan Saldana,J. (2014). Qualitative Data Analysis, A Methods Sourcebook, Edition 3. USA: Sage Publications. Terjemahan Tjetjep Rohindi Rohidi, UI-Press.

Moh. Nazir. (1998). Metode Penelitian. Jakarta: Ghalia Indonesia.

Murphy dan New. (1996). Brodifacoum Reisudes in Target and Non-Target Species Following an Aerial Poisoning Operation on Motuihe Island, Hauraki Gulf, New Zealand. New Zealand Journal of Ecology.

Nawawi, Hadari. (2008). Manajemen Sumber Daya Manusia Untuk Bisnis Yang Kompetitif. Yogyakarta : Gadjah Mada Univesity Press 
Nababan. (1992). Sosiolinguistik suatu pengantar. Jakarta : Gramedia Pustaka Utama.

Noor Salim. (2014). Teori dan Paradigma Penelitian Sosial.Yogyakarta:Tiara.

Rusminto, Nurlaksana Eko. (2010). Memahami Bahasa Anak-anak: Sebuah Kajian Analisis Wacana Panduan Bagi Guru, Orang Tua dan Mahasiswa Jurusan Bahasa. Bandar Lampung: Universitas Lampung.

Siregar, Bahren Umar. (2011). Seluk Beluk Fungsi Bahasa. Jakarta: Pusat Kajian Bahasa dan Budaya Universitas Katolik Indonesia Atma Jaya.

Supriatna, D. (2009). Pengenalan Media Pembelajaran. Bahan ajar untuk Diklat E -Training PPPPTK dan PLB. Bandung. PPPPTK dan PLB

Tarigan, Henry Guntur. (1990). Membaca Sebagai Suatu Keterampilan Berbahasa. Bandung: Angkasa.

Wibowo. (2011). Pemakaian Bahasa Alay sebagai Refleksi Kerentanan Masyarakat Bahasa: Kajian Sosiolinguistik". Tesis. Penelitian
Mono disiplin Fakultas Ilmu Budaya UGM

\section{Sumber Lain}

1. Astuti, Widya. (2013). Languages Attitudes Towards Written Alay Variety in Facebook Interaction.http://ejournal. upi.edu/index.php/psg/article/view/342

2. alaygenerator.co.cc (http://alaygenerat or.blogspot.co.id/).alaygenerator.co.cc (http://alaygenerator.blogspot.co.id/).

3. https://www.facebook.com/Andi Duank.)

4. (https://www.f4c3book.com/4ndi du4nk.

5. https://databoks.katadata.co.id/datapub lish/2018/04/11/berapa-jumlahpengguna-facebook-di-indonesia

6. http://carla.acad.umn.edu/speechacts/c omplaints.html (13/04/17)

7. https://www.google.com/search?q=Kat adata.co.id+\%282018\%29\&ie=utf$\underline{8 \& o e=u t f-8 \& \text { client }=\text { firefox }-\mathrm{b}-\mathrm{ab}}$

8. Meilinawati. (2014). http://fib.unpad.ac.id/peluncuran-10buku-karya-dosen-departemensusastra-kajian-budaya/ 